\title{
Violet stimulated luminescence: geo- or thermochronometer?
}

\author{
Ankjærgaard, Christina; Guralnik, Benny; Porat, N. ; Heimann, A. ; Jain, Mayank; Wallinga, J.
}

\section{Published in:}

Radiation Measurements

Link to article, DOI:

10.1016/j.radmeas.2015.01.011

Publication date:

2015

Document Version

Peer reviewed version

Link back to DTU Orbit

Citation (APA):

Ankjærgaard, C., Guralnik, B., Porat, N., Heimann, A., Jain, M., \& Wallinga, J. (2015). Violet stimulated luminescence: geo- or thermochronometer? Radiation Measurements, 81, 78-84.

https://doi.org/10.1016/j.radmeas.2015.01.011

\section{General rights}

Copyright and moral rights for the publications made accessible in the public portal are retained by the authors and/or other copyright owners and it is a condition of accessing publications that users recognise and abide by the legal requirements associated with these rights.

- Users may download and print one copy of any publication from the public portal for the purpose of private study or research.

- You may not further distribute the material or use it for any profit-making activity or commercial gain

- You may freely distribute the URL identifying the publication in the public portal

If you believe that this document breaches copyright please contact us providing details, and we will remove access to the work immediately and investigate your claim 


\title{
Violet stimulated luminescence: geo- or thermochronometer?
}

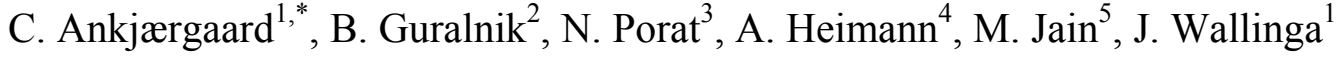 \\ ${ }^{1}$ Soil Geography and Landscape group \& Netherlands Centre for Luminescence dating, Wageningen University, \\ 6708 PB Wageningen, The Netherlands \\ ${ }^{2}$ Department of Earth Sciences, ETH-Zurich, 8092 Zurich, Switzerland \\ ${ }^{3}$ Geological Survey of Israel, 30 Malkhe Israel St., 95501 Jerusalem, Israel \\ ${ }^{4}$ Davidson Institute of Science Education, Weizmann Institute of Science, 76100 Rehovot, Israel \\ ${ }^{5}$ Centre for Nuclear Technologies, Technical University of Denmark, DTU Risø Campus, 4000 Roskilde, \\ Denmark \\ * Corresponding author: christina.ankjaergaard@gmail.com
}

\section{Keywords}

Violet stimulated luminescence, VSL dating, palaeosol, OSL-thermochronometry, hydrothermal fluids, Golan plateau.

\section{Highlights}

- We investigate the potential of VSL to date quartz from early Quaternary palaeosols (1.6 - 0.7 Ma old).

- The VSL signals show good reproducibility, dose response, thermal stability, and dose recovery.

- VSL ages from three palaeosols underestimate the independent K-Ar ages by $50 \%$ or more.

- It is possible that the VSL ages are correct, but have been reset by thermal anomalies.

- Further investigation of the natural VSL signal is needed to confirm these underestimating ages.

\begin{abstract}
The method of quartz optically stimulated luminescence (OSL) dating is widely used, but generally limited to the past $\sim 0.1$ million years (Ma) due to early saturation of the desired signal. Violet stimulated luminescence (VSL) of quartz has previously been shown as a promising alternative, with a dose saturation level $\sim 20$ times higher compared to that of OSL, excellent thermal stability on the $10^{11}$ year time scale, and agreement between VSL and OSL ages up to $\sim 0.3 \mathrm{Ma}$. Here we explore the usability of the VSL signal to date older quartz samples from palaeosols, whose ages are bracketed by K-Ar ages and palaeomagnetic data of the interbedded basalts, emplaced between 1.6 and 0.7 Ma. VSL ages from three palaeosols largely underestimate the independent ages of their overlying basalts. This can be explained either by a low-temperature thermal anomaly resetting the VSL signal in nature, and/or by an insufficient measurement protocol, unable to correctly translate the natural signal into the equivalent laboratory dose.
\end{abstract}




\section{Introduction}

Optically stimulated luminescence (OSL) from quartz is a widespread late-Quaternary dating method, used to estimate the time of sediment deposition, and is conventionally measured in the laboratory using blue light stimulation (Wintle and Murray, 2006; Preusser et al., 2009). Although quartz OSL has advantages over other dating methods owing to the ubiquity of the target mineral in geological environments, it is generally limited to $\sim 0.1 \mathrm{Ma}$ (Wintle, 2008). Several attempts have been made to extend this limit, including the use of thermally transferred OSL (Duller and Wintle, 2012 and references therein), slow OSL components (Singarayer et al., 2000), and isothermal thermoluminescence (ITL) (Jain et al., 2005). As initially demonstrated by Jain (2009), stimulation of quartz with violet light after bleaching of the blue-stimulated signal, accesses charge from a deep trap with an extended dose response in the kGy range, by far exceeding that of standard OSL (blue light stimulation). The subsequent work of Ankjærgaard et al. (2013) showed that this violet stimulated luminescence (VSL) signal is associated with a thermoluminescence (TL) trap at $\sim 380{ }^{\circ} \mathrm{C}$ with a thermal stability of $10^{11}$ years at $10^{\circ} \mathrm{C}$. The study furthermore reported a coherent VSL chronology agreeing with previous blue OSL ages $(n=9)$ on a timescale $<0.3$ $\mathrm{Ma}$, suggesting VSL as a good candidate for extending luminescence dating to the Ma range. The goal of this paper is to validate quartz VSL dating for the age range up to 1.6 Ma. We present VSL dating results for three quartz-bearing palaeosols bracketed between basaltic flows with K-Ar age constraints between 1.6-0.7 Ma (Mor and Steinitz, 1984).

\section{Methods and materials}

\subsection{Instrumentation}

VSL measurements were undertaken using a solid-state violet $(405 \mathrm{~nm})$ laser diode fitted onto an automated Risø TL/OSL-20 reader by a modification to the reader head, enabling stimulation with both blue $(470 \pm 30 \mathrm{~nm})$ and violet $(405 \mathrm{~nm})$ light. The focusable Nichia 405 $\mathrm{nm}$ laser diode had an effective output power of $\sim 35 \mathrm{~mW}$ at sample position, giving a uniform illumination area of $\sim 3.5 \mathrm{~mm}$ in diameter. To cut off the short wavelength tail, we used a combination of laser bandpass filter $402 \pm 15 \mathrm{~nm}$ (AHF F49-402) with a 3-mm-thick ITOS GG395 glass filter (ø $18 \mathrm{~mm}$ ). Luminescence was recorded using a photomultiplier tube (EMI QA 9235), equipped with a $7.5 \mathrm{~mm}$ Hoya-U340 filter, and a Semrock Brightline $340 \mathrm{~nm}$ interference filter (FF01-340/26, 凤 $45 \mathrm{~mm}$ ), the latter to minimize violet laser breakthrough into the photomultiplier tube. Samples were irradiated using a ${ }^{90} \mathrm{Sr} /{ }^{90} \mathrm{Y}$ source with a dose rate of $0.19 \pm 0.01 \mathrm{~Gy} . \mathrm{s}^{-1}$.

\subsection{Study area}

Nahal Orvim (33.141N, 35.680E) is situated in the Golan Heights (Israel), adjacent to the Dead Sea transform (DST), see Fig. 1a,b. In this tectonically complex zone the DST splits into a series of branching faults continuing northwards into Lebanon and Syria (Heimann and Ron, 1993). The Golan Heights is a basaltic plateau belonging to the largest volcanic field on the Arabian plate (Harrat Ash Shaam), whose Neogene basalt flows might be petrogenetically related to the tectonic activity on the DST (Weinstein and Garfunkel, 2014). At Nahal Orvim, a basalt sequence is exposed, comprising of several distinct flows, overlying a mid-Eocene limestone at the base of the section. Here we adopt the basalt numbering, NO-1 to 9, of Mor 


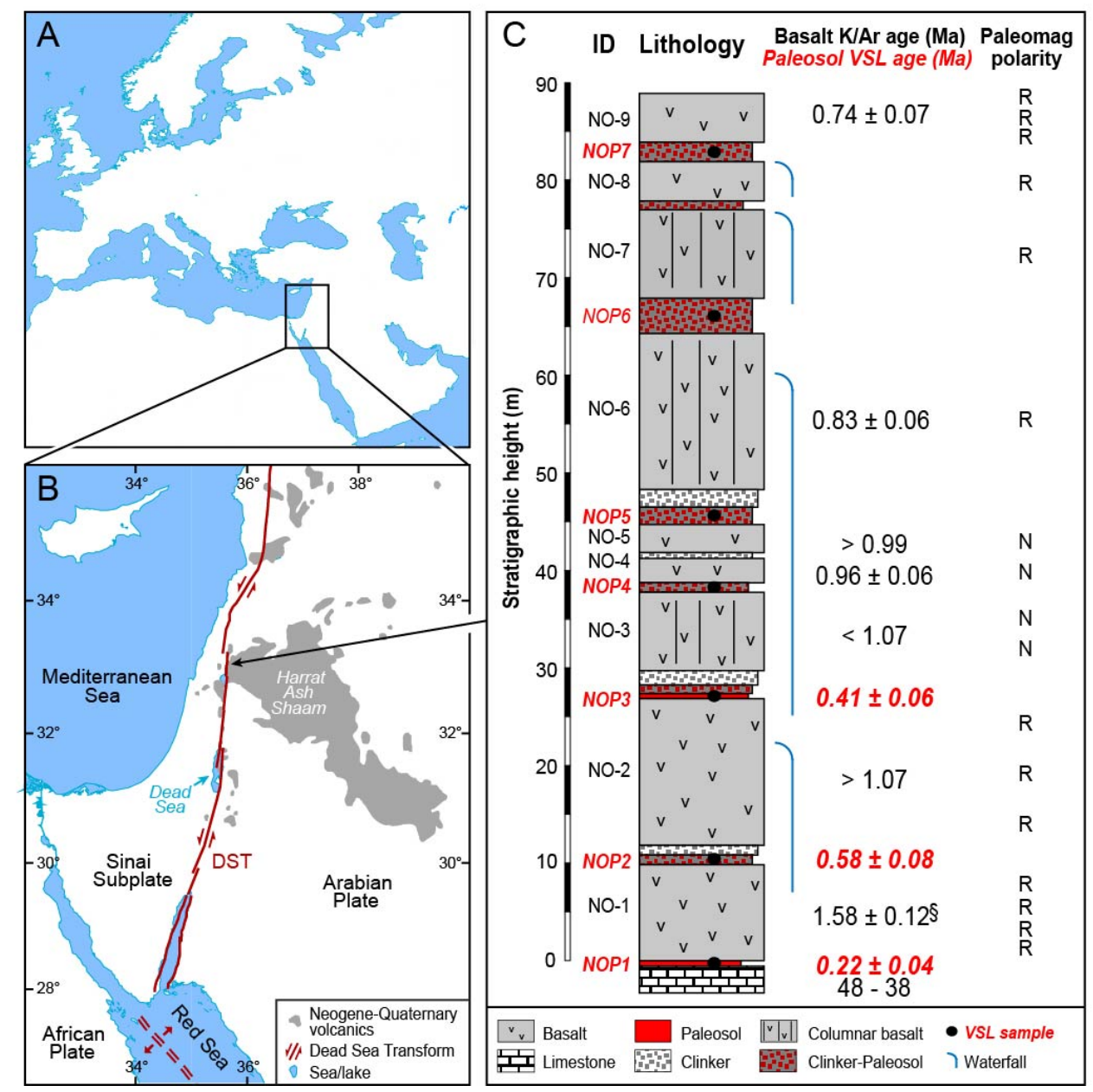

Figure 1: A+B: Location of the Nahal Orvim site in the Golan Heights (Israel). C: Stratigraphic section at Nahal Orvim, showing K-Ar ages (Mor and Steinitz, 1984; numbers in black), VSL ages (numbers in red), magnetic polarity data (Heimann and Ron, 1993), and VSL sample locations (black circles, this study). Further age constraints arising from combining the $\mathrm{K}$-Ar ages and magnetic polarity data are also indicated by $>$ and < ages. §It should be noted that the reported uncertainty on this age might be underestimated as the reproducibility/precision changes of up to $\sim 60 \%$ between repeated sub-sample measurements (Mor and Steinitz, 1984).

and Steinitz (1984) as illustrated in Fig. 1c. The mineralogy of the basalts is alkali-olivine; morphologically, the flows exhibit a massive or columnar structure, and usually feature a vesicular clinker at the base of each flow (Mor and Steinitz, 1984). Some flows are overlain by a red clay-rich and quartz-bearing palaeosol (NOP1-7, Fig. 1c), initially developed on the top of the exposed basalt substrate and subsequently baked and buried under the successive basaltic flow. The high density of the palaeosols is due to dewatering and formation of columnar 'baked' structures, often covered with manganese oxides (Singer and Ben-Dor, 1987). Since the basalts are devoid of quartz phenocrysts, the quartz grains embedded in the palaeosols are of a distal aeolian origin (rather than of local, pedogenic, source), and palaeosols with low quartz content are attributed to soil formation during periods of low aeolian input (Singer and Ben-Dor, 1987). Four of the basalt units (NO-1, -4, -6, -9) have been dated by Mor and Steinitz (1984) using K-Ar, bracketing the volcanic eruptions at this site between 1.58 and $0.74 \mathrm{Ma}$ (ages in black, Fig. 1c). These ages are further supported by palaeomagnetic polarity data, sampled at the same site with a higher resolution (Heimann and 
Ron, 1993), and attributing three units (NO-3, -4, -5) to the normal polarity of the Jaramillio sub-chron (1.07-0.99 Ma; Singer, 2014, and references within). The combination of K-Ar and palaeomagnetic data allows further refinement of the basalt ages of units NO-2, -3 , and NO-5. Newly obtained 40Ar/39Ar ages for the section corroborate the chronology and will be reported elsewhere.

\subsection{Sample preparation}

Palaeosol samples were collected into light-tight black bags at night under a photographic red lamp, after scraping the exposed outcrops $>10 \mathrm{~cm}$ inward. The collected materials were then gently crushed in the laboratory, wet-sieved between 75 and $125 \mu \mathrm{m}$, and etched with $10 \% \mathrm{H}_{2} \mathrm{O}_{2}$ and $10 \% \mathrm{HCl}$ to remove organic matter and carbonates, respectively. The quartz fraction was obtained via magnetic (rather than heavy-liquid) separation in two steps using currents of $0.5 \mathrm{~A}$ and $1.4 \mathrm{~A}$ to rid of magnetic and iron-coated grains, respectively (Porat, 2006). The resulting quartz fractions were visually checked under the microscope and contained only a few plagioclase feldspar grains, which were further removed by a 20 min $40 \% \mathrm{HF}$ etching followed by $\mathrm{HCl}$ for $40 \mathrm{~min}$.

VSL measurements were carried out on aliquots consisting of quartz grains mounted on silicone-sprayed stainless steel discs, covering the central $2.5 \mathrm{~mm}$ diameter. The VSL signals were measured for $500 \mathrm{~s}$; net signals used for analysis were obtained by integrating the first 0 $3 \mathrm{~s}$ of the optical stimulation, and corrected for 'background' taken from last $30 \mathrm{~s}$ of the decay curve.

\subsection{Dose rate determination}

The chemical composition of the sampled palaeosols and basalts was determined at Activation Laboratories Ltd. (Ancaster, Ontario) by inductively coupled plasma (ICP) optical emission spectrometry (OES), and mass spectrometry (MS). Major oxides were determined on a Varian Vista 735-ES ICP-OES; all other elements were measured on a Perkin Elmer Sciex ELAN 6100/9000 ICP-MS. For the radioactive elements used for dose-rate calculation $(\mathrm{U}$, Th and $\mathrm{K})$, we used conservative precision and reproducibility uncertainties of $5 \%\left(\mathrm{~K}_{2} \mathrm{O}\right)$, $10 \%$ ( $\mathrm{U}$ and $\mathrm{Th}$ ), see Table 1. Gamma spectrometry measurements confirmed that no significant radioactive disequilibrium was detected in any of the samples. Dose rates to the thin $(\sim 20-40 \mathrm{~cm})$ soils were modeled to include a gamma contribution from their adjacent basalt (and in one case, limestone) layers following Aitken (1985). For further details on the dose rate calculations, see the caption to Table 1.

\section{VSL signal behaviour}

\subsection{Protocol and dose response curves}

A change in VSL decay curve shape between the natural and the corresponding test dose has been previously reported and discussed in Ankjærgaard et al. (2013). Applying the protocol of Ankjærgaard et al. (2013; listed here in Table 2a) on quartz from Nahal Orvim resulted in significant changes in sensitivity and decay curve shape, motivating us to revert to the protocol of Jain (2009; listed here in Table 2b), and eventually adopt a composite protocol (listed in Table 2c). The main difference of the new protocol compared to Ankjærgaard et al. (2013) is a lower preheat temperature employed for longer time, and separation of the preheat 


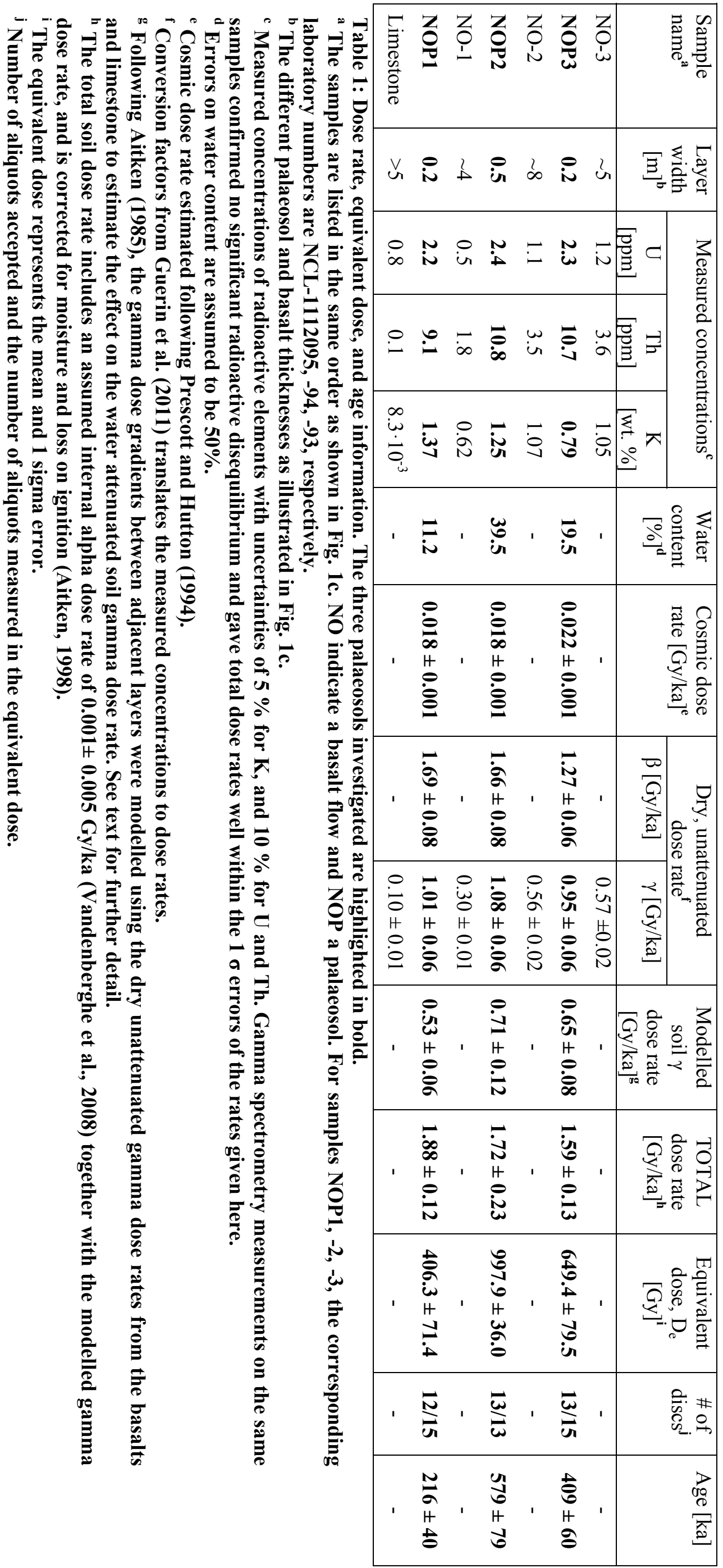




\begin{tabular}{|c|c|c|c|c|}
\hline Step & $\begin{array}{l}\text { a) SAR-VSL } \\
\text { Ankjærgaard et al., (2013) }\end{array}$ & $\begin{array}{l}\text { b) SAR-VSL } \\
\text { (Jain, 2009) }\end{array}$ & $\begin{array}{l}\text { c) VSL protocol used in this } \\
\text { study }\end{array}$ & \\
\hline 1 & Regeneration dose & Regeneration dose & Regeneration dose & \\
\hline 2 & & Preheat $\left(340^{\circ} \mathrm{C}, 10 \mathrm{~s}\right)$ & Preheat $\left(300^{\circ} \mathrm{C}, 100 \mathrm{~s}\right)$ & \\
\hline 3 & Blue bleach $\left(280^{\circ} \mathrm{C}, 100 \mathrm{~s}\right)$ & Blue bleach $\left(125^{\circ} \mathrm{C}, 100 \mathrm{~s}\right)$ & Blue bleach $\left(125^{\circ} \mathrm{C}, 100 \mathrm{~s}\right)$ & \\
\hline 4 & $\operatorname{VSL}\left(125^{\circ} \mathrm{C}, 100 \mathrm{~s}\right)$ & $\operatorname{VSL}\left(50^{\circ} \mathrm{C}, 500 \mathrm{~s}\right)$ & $\operatorname{VSL}\left(30^{\circ} \mathrm{C}, 500 \mathrm{~s}\right)$ & $\mathrm{L}_{\mathrm{i}}$ \\
\hline 5 & Test dose & Test dose & Test dose & \\
\hline 6 & & Cutheat $\left(340^{\circ} \mathrm{C}, 1 \mathrm{~s}\right)$ & Preheat $\left(290^{\circ} \mathrm{C}, 100 \mathrm{~s}\right)$ & \\
\hline 7 & Blue bleach $\left(270^{\circ} \mathrm{C}, 100 \mathrm{~s}\right)$ & Blue bleach $\left(125^{\circ} \mathrm{C}, 100 \mathrm{~s}\right)$ & Blue bleach $\left(125^{\circ} \mathrm{C}, 100 \mathrm{~s}\right)$ & \\
\hline 8 & $\operatorname{VSL}\left(125^{\circ} \mathrm{C}, 100 \mathrm{~s}\right)$ & $\operatorname{VSL}\left(50^{\circ} \mathrm{C}, 500 \mathrm{~s}\right)$ & $\operatorname{VSL}\left(30^{\circ} \mathrm{C}, 500 \mathrm{~s}\right)$ & $\mathrm{T}_{\mathrm{i}}$ \\
\hline 9 & Violet bleach $\left(280^{\circ} \mathrm{C}, 200 \mathrm{~s}\right)$ & Blue bleach $\left(500^{\circ} \mathrm{C}, 100 \mathrm{~s}\right)$ & Violet bleach $\left(380^{\circ} \mathrm{C}, 200 \mathrm{~s}\right)$ & \\
\hline
\end{tabular}

Table 2: VSL protocols used in previous works, and the VSL protocol used in this study.

and the blue OSL wash. The main advantage of the protocol in Table $2 \mathrm{c}$ is a reduction in decay curve shape change between the natural and the test dose curves, which can lead to dose underestimations (Ankjærgaard et al., 2013). Further support for the validity of this protocol for the Nahal Orvim samples is obtained via dose recovery tests in Section 3.3.

Fig. 2 shows the VSL dose response for sample NOP2 using protocol 2c. Good recycling within $10 \%$ (open symbol), and no significant signal recuperation for the zero dose point are observed. After testing several alternatives, the experimental data are best-fitted with a sum of two saturating exponentials (cf. Ankjærgaard et al., 2013), with two characteristic doses, $\mathrm{D}_{0,1}$ $<<\mathrm{D}_{0,2}$ (Gy). The $\mathrm{D}_{0,2}$ of $\sim 1.6 \mathrm{kGy}$ is higher than that reported by Jain (2009) using protocol $2 \mathrm{~b}$, but about half of that reported by Ankjærgaard et al. (2013) using protocol 2a. This difference in $\mathrm{D}_{0}$ is the result from the use of different protocols as well as sample-specific behaviour.

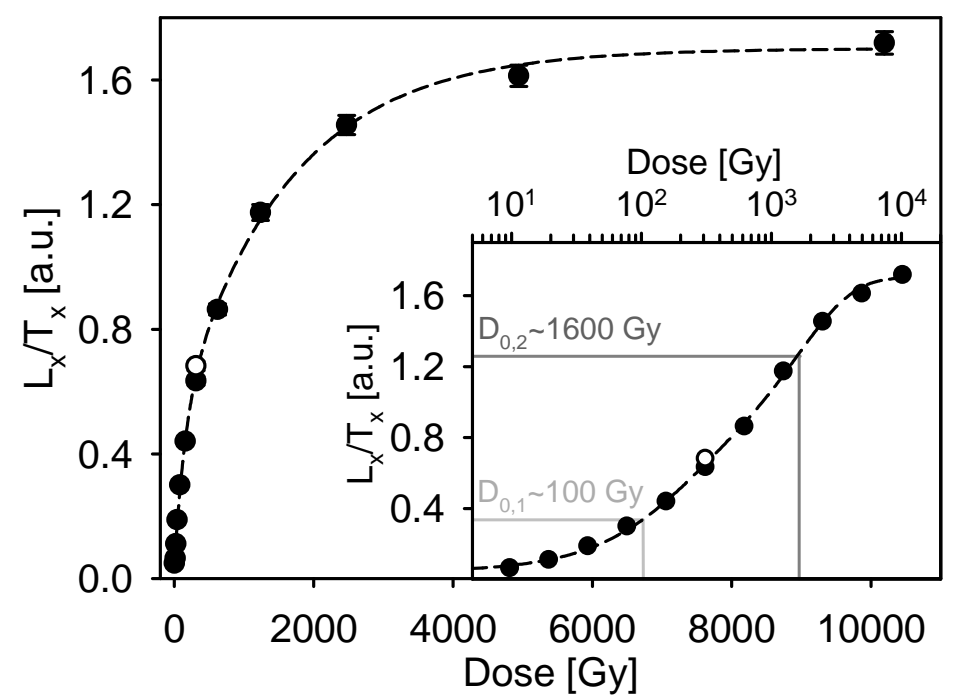

Figure 2: Dose response from sample NOP2 using protocol 2c. To observe the goodness-of-fit at the lower dose range, the same data and fit are repeated on a semi-logarithmic plot (inset). Dashed line corresponds to the best-fit sum of two saturating exponentials, with characteristic doses $D_{0,1} \sim 100 \mathrm{~Gy}$ and $D_{0,2} \sim 1600 \mathrm{~Gy}$. 


\subsection{Thermal stability}

The thermal stability of the VSL signal for samples from four different sedimentary environments has been previously reported to have very similar thermal stabilities of $\sim 10^{11}$ years at $10{ }^{\circ} \mathrm{C}$ (Ankjærgaard et al., 2013). In order to compare this to the thermal stability of quartz from Nahal Orvim, and possibly quantify the effects of the new protocol, one aliquot (NOP2) was subjected to thermal holding experiments following a modified protocol $2 \mathrm{c}$, as explained below. Thermally-depleted signals were obtained by giving a dose of $400 \mathrm{~Gy}$, preheating to $300{ }^{\circ} \mathrm{C}$ for $100 \mathrm{~s}$, bleaching by blue light at $125^{\circ} \mathrm{C}$ for $100 \mathrm{~s}$, and holding at temperature $T\left[{ }^{\circ} \mathrm{C}\right]$ for time $t[\mathrm{~s}]$, prior to violet stimulation at $30{ }^{\circ} \mathrm{C}$. A test signal (to correct for potential sensitivity changes) was obtained in a similar fashion, but after a dose $200 \mathrm{~Gy}$, preheat to $290{ }^{\circ} \mathrm{C}$ for $100 \mathrm{~s}$, and blue light bleaching at $125^{\circ} \mathrm{C}$ for $100 \mathrm{~s}$. Each holding cycle was concluded with a violet bleach at $380{ }^{\circ} \mathrm{C}$ for $200 \mathrm{~s}$ before repeating the experiment for different $T$ and $t$. The resulting isothermal decay curves are shown in Fig. 3; due to a non-first order loss, the effective thermal lifetimes $\tau_{\text {eff }}$ were obtained via simultaneous fitting of the six isothermal depletion curves with a stretched hyperbolic function (Ankjærgaard et al., 2013, their equation 2). The 'stretching factor' $c$ is a dimensionless parameter common to the six fits, representing the deviation from simple first-order kinetics (where $c=0$ ). For the fits in Fig. 3, $c=1.68 \pm 0.07$, which is similar to the values reported in Ankjærgaard et al. (2013). The inset to Fig. 3 shows the effective lifetime, $\tau_{\text {eff }}$, plotted against scaled inverse temperature $1 / \mathrm{k}_{\mathrm{B}} \mathrm{T}$; the slope and the intercept of a regressed straight line corresponds to the VSL thermal trap depth, $E[\mathrm{eV}]$, and the natural logarithm of the escape factor, $s\left[\mathrm{~s}^{-1}\right]$. The values for NOP2 are $E=1.90 \pm 0.03 \mathrm{eV}$ and $\log _{10}(s)=14.3 \pm 0.3 \mathrm{~s}^{-1}$, resulting in a thermal lifetime of $\sim 7 \cdot 10^{10}$ years at $10{ }^{\circ} \mathrm{C}$, comparable to previously reported values $\left(E \sim 1.9 \mathrm{eV}\right.$ and $\log _{10}(s) \sim 14.7 \mathrm{~s}^{-1}$, averages from Ankjærgaard et al., 2013), and predicting negligible thermal loss on the timescale of interest for dating $\left(10^{6}\right.$ years).

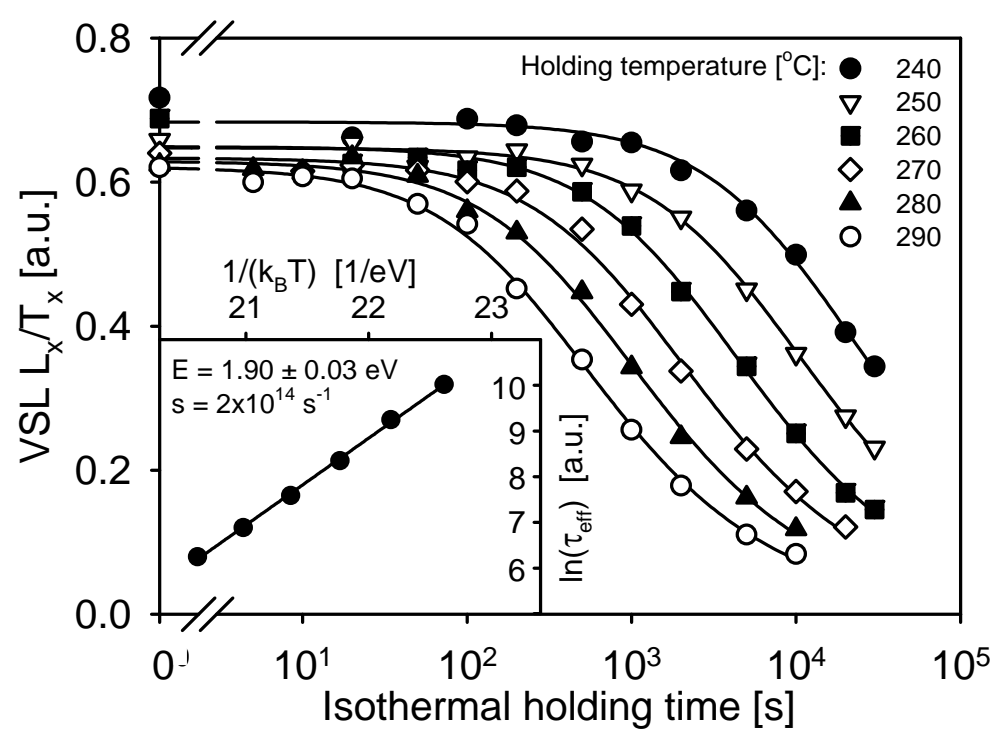

Figure 3: Isothermal holding of sample NOP2 at temperatures between 240 and $290{ }^{\circ} \mathrm{C}$. Effective isothermal lifetimes $\tau_{\text {eff }}$, are obtained from simultaneously fitting the decay of each individual temperature with a compressed hyperbola (Eq. 2 in Ankjærgaard et al., 2013). Inset: the linear regression of $\ln \left(\tau_{\text {eff }}\right)$ vs. the inverse of the corresponding holding temperature yields the Arrhenius parameters $E$ and $s$ (see text). 


\subsection{Dose recovery and age estimates}

In retrospective dosimetry and in dating, the aim is to estimate the radiation dose absorbed by a sample prior to any laboratory treatment. To test if a measurement protocol is suitable to estimate such doses, a 'dose recovery' test is performed; a known laboratory dose is administered to a sample prior to any heat treatment and subsequently recovered using the protocol. If the recovery is successful, the protocol is expected to adequately correct for any sensitivity change during the first SAR cycle (Wintle and Murray, 2006). To test protocol 2c, we performed dose recovery tests on quartz from four palaeosols (NOP1, NOP2, NOP3, NOP5). Samples were bleached by violet light at room temperature for $600 \mathrm{~s}$ prior to irradiation with known beta doses between 1 and $3 \mathrm{kGy}$, which were then treated as unknowns, and recovered using the protocol. The residual dose level following the violet bleach for $600 \mathrm{~s}$ was estimated on separate aliquots (NOP1 80 Gy; NOP2 170 Gy; NOP3 $\sim 40 \mathrm{~Gy}$; NOP5 30 Gy) and subtracted from the recovered dose. A dose recovery (one aliquot of sample NOP2; given dose of $3 \mathrm{kGy}$ ) is shown in Fig. $4 \mathrm{a}$; the inset illustrates that for this aliquot, no observable change in the decay curve occurs between the given ( $3 \mathrm{kGy})$ and the test dose, implying no differential sensitisation between the two measurements (Ankjærgaard et al., 2013). Aliquots showing no growth in the dose response and/or with a recycling ratio deviating with more than $15 \%$ from unity were rejected. Dose recovery experiments are summarized in Fig. 4b; the recovered doses are all normalized by their known given doses, and should be considered successful if the ratio lies within $10 \%$ of unity (Murray \& Wintle, 2006). All results fall within $2 \sigma$ of unity, and for three out of four samples (NOP1, NOP2, and NOP5), the dose recovery ratio is within $10 \%$ of unity. Sample NOP3 overestimates the given dose by $19 \%$, despite absence of obvious signal anomalies. Overall, we interpret the dose recoveries as successful, indicating that the protocol can adequately estimate known doses.

To test the performance of the VSL chronometer on the Ma timescale, we focused on dating the three oldest palaeosols which, unlike the layers above, contain abundant quartz. Equivalent dose estimates were obtained by averaging over the accepted aliquots and are listed with one standard error of the mean (Table 1). The resulting VSL ages all significantly underestimate the independent age control (red numbers in Fig. 1c). NOP1 is dated to $0.22 \pm 0.04 \mathrm{Ma}$, in contrast to the overlying basalt age of $1.58 \pm 0.12 \mathrm{Ma}$. NOP2 has an age of $0.58 \pm 0.08 \mathrm{Ma}$, but is capped by a $>1.07 \mathrm{Ma}$ basalt, and finally, NOP3 is dated to $0.41 \pm 0.06$ $\mathrm{Ma}$, although it developed before 1.07-0.96 Ma. Compared to the independent age constraints, the VSL ages underestimate by $>50 \%$ (NOP2 and NOP3), and $>80 \%$ (NOP1), despite wellbehaved VSL characteristics of signal shape reproducibility, dose response, thermal stability and dose recovery. While only based on three samples, the observed age underestimation seems to decrease with elevation. If these ages are correct, they may reflect a thermal history (discussed in Section 4); however, there also remains the possibility that the ages themselves are erroneous (discussed in Section 5). 

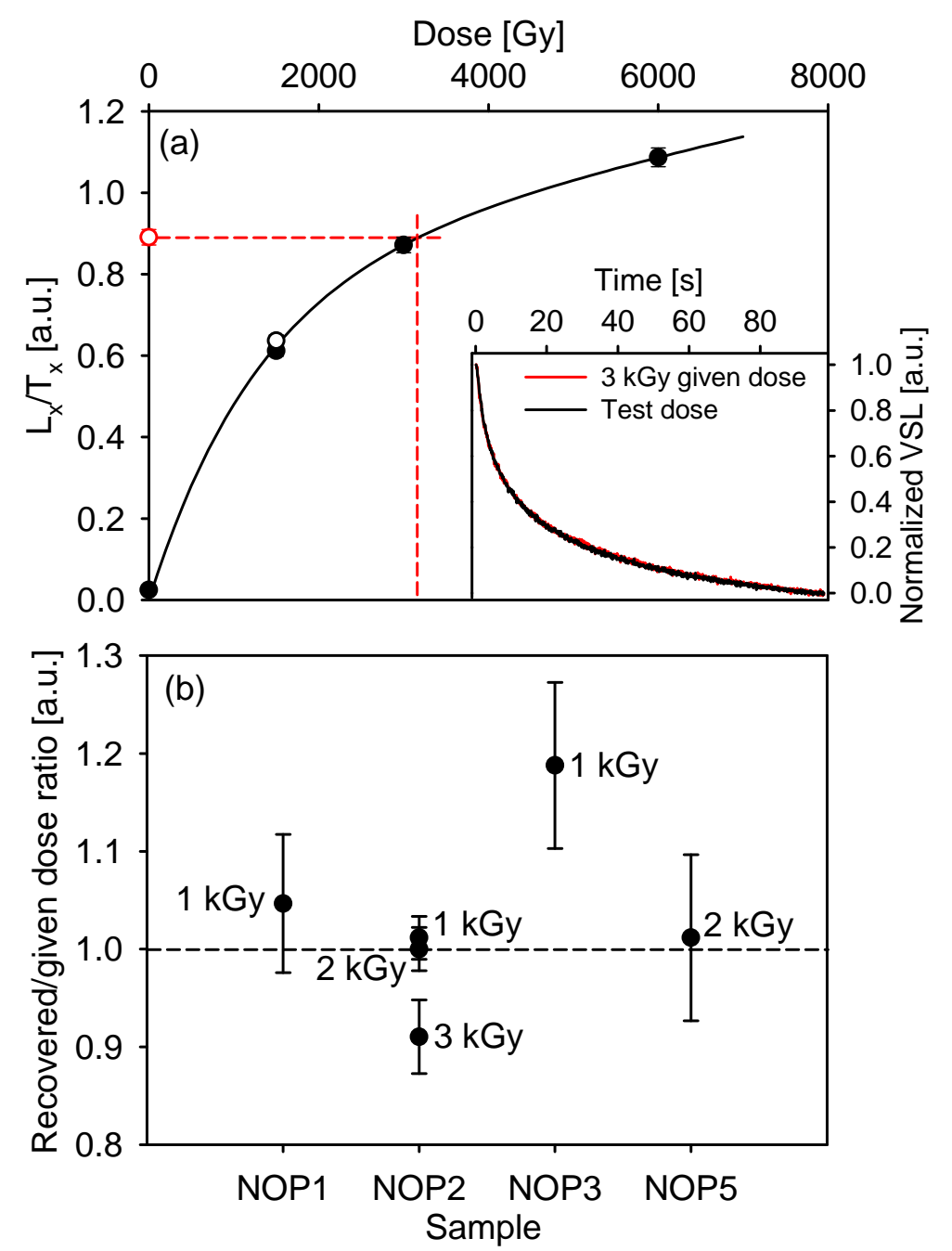

Figure 4: Dose recovery results for the protocol in Table 2c. (a) recovery of $3 \mathrm{kGy}$ from sample NOP2 (inset shows given and regenerated decay curves, indicating no sensitivity change between the two). Note that due to the small number of dose points, we extrapolate the mimicked $L_{n} / T_{n}$ onto a saturating exponential plus linear dose response function (black line) and not a double saturating exponential as in Fig. 2. (b) Recovered/given dose ratios are within $10 \%$ of unity for 3 out of 4 samples; $20 \%$ dose overestimation in sample NOP3 is in contrast to its otherwise agreeable signal characteristics.

\section{Thermochronological interpretation of age underestimates}

In the above comparison of VSL dates against independent basalt ages, we made an implicit assumption that both chronometers should date the same event of basalt emplacement, corresponding to the simplest geological scenario. However, the two chronological methods (VSL and K-Ar) use signals with very different thermal stabilities: while Ar retention in basaltic glass occurs almost immediately after its solidification at $\sim 500$ ${ }^{\circ} \mathrm{C}$ (cf. Caroll, 1991), the accumulation of trapped electrons (as quantified by e.g. OSL, VSL, TL) typically starts hundreds of degrees lower (Guralnik et al., 2013). Thus, a more complex scenario is possible, in which VSL signals are thermally reset by relatively low temperatures, having no effect on the K-Ar dates. Low thermal stabilities of trapped charge may in fact be used for tracing the cooling histories of rocks, referred to as luminescence thermochronometry (Herman et al., 2010; Guralnik et al., 2013).

In thermochronometry, it is recognised that a multitude of cooling pathways may produce exactly the same age, well represented by three extreme scenarios (Wu et al., 2015). Scenario 
(i), implicitly discussed before, is that of a nearly instantaneous cooling of the baked palaeosol to typical surface temperature of $\sim 30{ }^{\circ} \mathrm{C}$. In this scenario, its VSL age should indeed replicate the K-Ar age of its overlying basalt. However, two additional scenarios exist: (ii) that of a monotonic cooling history, and (iii) of an indefinite storage at an elevated temperature $T_{a p p}$. The above three scenarios are the simplest, and have analytical solutions (Guralnik et al., 2013); more complicated scenarios (e.g. a periodic heating) may also produce the observed ages, but require additional constraints from other thermochronometric systems (Reiners and Brandon, 2006). The conversion of a measured trap filling ratio $n / N$ into an equivalent storage temperature $T_{a p p}$ requires knowledge of the natural electron trapping rate $\dot{D} / D_{0}$, and the Arrhenius parameters $E$ and $s$; to constrain the closure temperature $\left(T_{C}\right)$ of a monotonically cooling system, one additionally needs to know the cooling rate (Dodson, 1973; Guralnik et al., 2013).

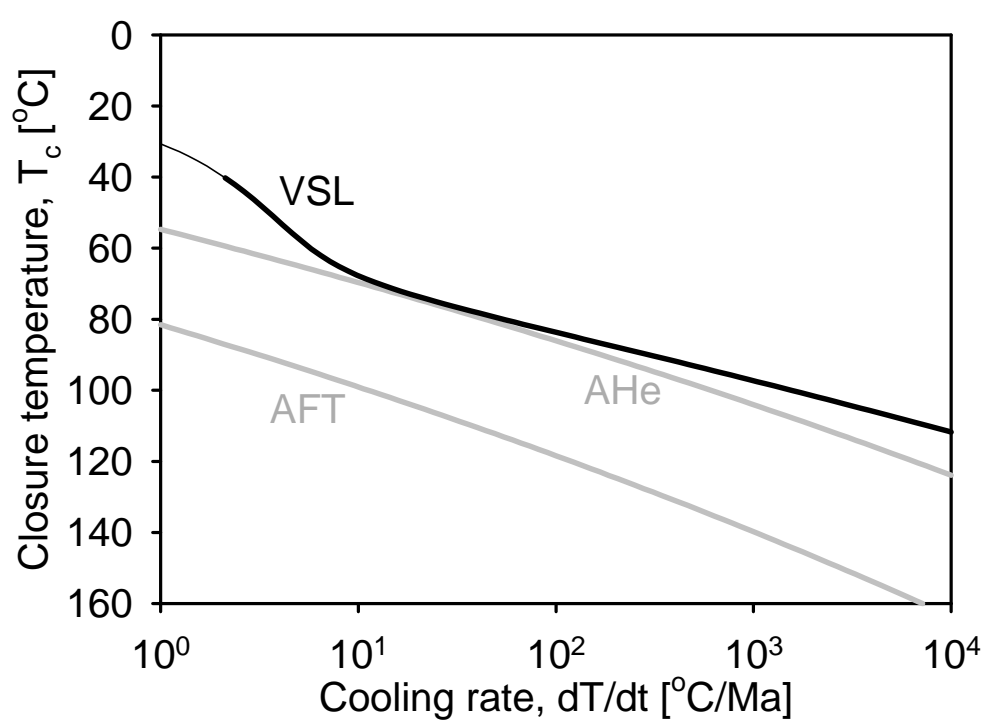

Figure 5: Predicted closure temperature as a function of cooling rate for VSL (black), apatite U-Th/He (AHe, grey), and apatite fission track (AFT, grey) thermochronometers. See text for kinetic parameters of the VSL system, and Reiners and Brandon (2006) for thermal stability of AHe and AFT. Notice the similarity between the predicted closure for VSL and AHe systems across a wide range of cooling rates. The thin line segment (in VSL) corresponds to a region where VSL signals would appear saturated, yielding only minimum ages (i.e. allowing to obtain a maximum cooling rate only).

Thermal scenarios (ii) and (iii) are further demonstrated for sample NOP2. The VSL dose response is best described by a sum of two saturating exponentials (Fig. 2). Simultaneous fitting of VSL signals from three aliquots yields a best-fit of $D_{0,1}=87 \pm 11$ Gy ( $28 \%$ relative contribution) and $D_{0,2}=1487 \pm 115$ Gy ( $72 \%$ contribution). Since the equivalent dose of this sample is $998 \pm 36$ Gy (see Table 1), we can assume that the lower $D_{0,1}$ component is thermally stable and in saturation, while the higher $D_{0,2}$ is only filled to a level of $16 \pm 2 \%$ of full saturation. The apparent storage temperature can be found using Equation A.10b from Guralnik et al. (2013):

$$
T_{a p p}=-E / k_{B} \ln \left[(N / n-1) \dot{D} / D_{0} s\right]
$$


Using the filling ratio $(n / N=0.16 \pm 0.02)$, together with the $E$ and $s$ given in Fig. 3, and a $\dot{D}=1.72 \pm 0.23 \mathrm{~Gy} / \mathrm{ka}$ (Table 1), the apparent storage temperature can be estimated to $T_{a p p}=83 \pm 7{ }^{\circ} \mathrm{C}$. Considering the alternative scenario of monotonic cooling, VSL closure temperatures $\left(T_{C}\right)$ are calculated for this sample (following Guralnik et al., 2013) and shown in Fig. 5 for a range of cooling rates, alongside closure temperatures of apatite U-Th/He (AHe) and apatite fission track (AFT) systems (Reiners and Brandon, 2006). The resemblance of the VSL and AHe closure temperatures indicates comparable thermal stabilities of the two methods; for example, for a reference cooling rate of $10{ }^{\circ} \mathrm{C} / \mathrm{Ma}$, the closure in both systems occurs at $T_{C} \sim 70{ }^{\circ} \mathrm{C}$. However, unlike in the AHe method, the VSL chronometer is further subject to signal saturation, which allows to constrain the minimal possible cooling rate $(\mathrm{Wu}$ et al., 2015). For the observed trap filling of $n / N=0.16$, and a final cooling temperature of $\sim 30$ ${ }^{\circ} \mathrm{C}$ (representing typical daytime temperatures in the Mediterranean climate), the monotonic cooling rate of sample NOP2 can be constrained to $>4400 \pm 1300{ }^{\circ} \mathrm{C} / \mathrm{Ma}$, with an associated $T_{C}$ of $>107 \pm 10^{\circ} \mathrm{C}$.

\section{Discussion}

To evaluate the thermochronometric interpretation, we start by noting that the ad-hoc deconvolution of the VSL growth curve into two saturating exponential components is purely empirical, lacking any physical validation. The presence of two such components in the growth curve would imply two charge reservoirs with different capacities yet with an assumed identical thermal stability. Whether such distinct reservoirs exist or not, and whether they correspond to different electron traps, remains to be addressed in the future, and we plan to do so. Our current thermochronometric reconstruction is based on the filling ratio of the nonsaturated $\left(\mathrm{D}_{0,2}\right)$ component. If we assume that the separation into components is reasonable, we can further compare the obtained results to independent geological constrains.

The reconstructed storage temperature for sample NOP2 $\left(\sim 80^{\circ} \mathrm{C}\right)$ is about $\sim 50{ }^{\circ} \mathrm{C}$ higher than typical surface temperatures at the Nahal Orvim site today; it is therefore unlikely, that the NOP2 sample experienced a continuous storage at $\sim 80{ }^{\circ} \mathrm{C}$ during the past $\sim 0.5 \mathrm{Ma}$. The alternative interpretation of a continuous regional bedrock cooling at $\sim 4000{ }^{\circ} \mathrm{C} / \mathrm{Ma}$ is also unrealistic. Although the Golan Plateau experiences uplift relative to the subsiding Hula basin, cooling rates due to faulting and erosion are expected to be $\sim 3$ orders of magnitude slower (Heimann and Steinitz, 1989). To summarize, if we are to accept the thermal resetting of VSL signals at Nahal Orvim, neither the constant storage at elevated temperature, nor the monotonic cooling scenarios apply. On the other hand, these data may be explained by discrete heating events in the past. Such events at an active rift margin are not unlikely: anomalously high water temperatures have been reported from the Shamir artesian drillhole, just $2 \mathrm{~km}$ northwest of the Nahal Orvim site (Siebert et al., 2014), as well as $40 \mathrm{~km}$ south of the Nahal Orvim site (Gvirtzman et al., 1997; Roded et al., 2013; Shalev et al., 2013).

A similar study undertaken by Ogoh et al. (1993) in a volcanic setting in New Mexico, reported ESR age underestimations of the eruptions ages at Valles Caldera from fission track, $\mathrm{U}-\mathrm{Th}$, and ${ }^{40} \mathrm{Ar} /{ }^{39} \mathrm{Ar}$, arguing that the ESR signal intensity was possibly partially reduced by several later thermal events. This hypothesis was further supported by Lepper and Goff (2007) measuring quartz OSL and polymineral fine silts IRSL from baked colluvial sediment layers from the same site, obtaining ages in agreement with those of ESR. More recently, 
similar age underestimates were observed in a comparable volcanic environment by Tsukamoto et al. (2011) obtaining IRSL ages from plagioclase in bulk basalts measurements. All these studies support the possibility that basaltic sequences in volcanically active areas undergo repeated heating events both due to contact with hot lava, but more importantly due to heating with thermal fluids, which may persist in that region long after the surface basalts are cooled. However, the present VSL data should only be taken as a hint to past thermal events, and not as their proof. Whether or not temperatures as high as $80{ }^{\circ} \mathrm{C}$ occurred at the site in the past $1 \mathrm{Ma}$, and whether the separation into growth components is justifiable, remains to be further explored, e.g. using apatite U-Th/He (Fig. 5) and/or additional luminescence experiments.

Although thermal resetting of the VSL signal could be a cause for the apparent age underestimations, an equally plausible explanation is the potential inability of the VSL measurement protocol (Table 2c) to convert the natural signal into a palaeodose. One of the main assumptions in dating is that the growth of the dose received in nature can be regenerated in the laboratory via an appropriate protocol to measure the dose response curve (Wintle and Murray, 2006). This assumption is rather difficult to test, because it requires a site providing known age samples which are evenly distributed over the dose range of interest and which have small variations in dose rate between samples. Only a handful of studies have so far attempted to evaluate this assumption for quartz OSL (Chapot et al., 2012; TimarGabor and Wintle, 2013; Lai and Fan, 2014). Based on blue OSL signals measured in loess stratigraphies, all of the above studies observed that for doses exceeding $\sim 150 \mathrm{~Gy}$, the natural and laboratory-regenerated dose response curves diverge, causing a progressive underestimation of ages at all larger doses. As Ankjærgaard et al. (2013) estimated VSL doses of up to $\sim 200$ Gy in agreement with those obtained from OSL, perhaps there is a similar tendency for the natural and regenerated VSL dose response curves to deviate for higher doses, thereby causing the observed underestimations. The ages in Nahal Orvim span between 1.6-0.7 Ma (Fig. 1c) with expected doses ranging between 3-1 kGy; the lack of younger palaeosols capped by basalts at this site limits the characterisation of the natural VSL dose response curve only to high doses. Therefore, the two assumptions that (i) the natural VSL growth curve has the same shape as that measured in the laboratory and (ii) both the natural and regenerated VSL growth curves can be described by a sum of saturating exponentials (as discussed above), can be neither verified nor disproved at this stage. If the natural and regenerated signals with dose are found to deviate, this could easily explain the large dose underestimation, but if they are found to agree, this would be in support of the thermal resetting scenario. For further progress with the VSL method, it is therefore imperative to investigate the natural VSL signal growth curve shape; a test study in a more suitable geological site is currently in progress.

\section{Conclusion}

In this work we investigated a classic geological section of nine basaltic flows interbedded with palaeosols, with the aim of validating VSL dates from the quartz in the soil layers against independent basalt K-Ar ages. Despite well-behaved VSL characteristics of signal shape reproducibility, dose response, thermal stability, and dose recovery, all three of the dated samples substantially underestimate the soil baking events by $\sim 50 \%$ or more. Two possible 
interpretations of such a severe age underestimation are (i) the ages are correct, but have been reset by thermal anomalies not affecting the more thermally stable K-Ar system, or (ii) the ages are erroneous, due to the inapplicability of the VSL protocol and/or perhaps samplespecific issues. To decide which of these interpretations is correct, either the apatite $\mathrm{U}-\mathrm{Th} / \mathrm{He}$ and fission track thermochronometers should be further explored, or the natural VSL growth curve shape should be determined. Unfortunately, the latter is not possible at the study site due to lack of soil layers younger than $0.8 \mathrm{Ma}$, needed to constrain the low-dose VSL response.

\section{Acknowledgements}

The authors would like to thank Dr. Doron Mor for locating and re-sampling the original basalt units from Mor and Steinitz (1984). Further thanks are due to Gala Faerstein and Iaad Suaad (Geological Survey of Israel) for assistance in fieldwork. Finally, Dr. Sumiko Tsukamoto is thanked for constructive review comments, and Dr. Sébastien Huot for additional comments and Editorial handling. BG was supported by Swiss National Foundation Grant 200021-127127. This project has been financed by the Dutch Technology Foundation STW (STW.10502) and Netherlands Organisation for Scientific Research, NWO VENI (grant 863.13.023).

\section{References}

Aitken, M. J., 1998. Introduction to Optical Dating. Oxford University Press.

Aitken, M.J., 1985. Thermoluminescence Dating. London: Academic Press.

Ankjærgaard, C., Jain, M. and Wallinga, J., 2013. Towards dating Quaternary sediments using the quartz Violet Stimulated Luminescence (VSL) signal. Quaternary Geochronology 18, 99-109.

Carroll, M.R., 1991. Diffusion of Ar in rhyolite, orthoclase and albite composition glasses. Earth and Planetary Science Letters 103, 156-168.

Chapot, M.S., Roberts, H.M., Duller, G.A.T., Lai, Z.P., 2012. A comparison of natural- and laboratory-generated dose response curves for quartz optically stimulated luminescence signals from Chinese Loess. Radiation Measurements 47, 1045-1052.

Dodson, M.H., 1973. Closure temperature in cooling geochronological and petrological systems. Contributions to Mineralogy and Petrology 40, 259-274.

Duller, G.A.T., Wintle, A.G., 2012. A review of the thermally transferred optically stimulated luminescence signal from quartz for dating sediments. Quaternary Geochronology 7, 6-20.

Guérin, G., Mercier, N., Adamiec, G., 2011. Dose-rate conversion factors: update. Ancient TL 29, 5-8.

Guralnik, B., Jain, M., Herman, F., Paris, R.B., Harrison, T.M., Murray, A.S., Valla, P.G., Rhodes, E.J., 2013. Effective closure temperature in leaky and/or saturating thermochronometers. Earth and Planetary Science Letters 384, 209-218.

Gvirtzman, H., Garven, G., Gvirtzman, G., 1997. Thermal anomalies associated with forced and free ground-water convection in the Dead Sea rift valley. Geological Society of America Bulletin 109, 1167-1176. 
Heimann, A. and Ron, H.,1993. Geometric changes of plate boundaries along part of the northern Dead Sea Transform: Geochronologic and palaeomagnetic evidence. Tectonics $12,477-491$.

Heimann, A. and Steinitz, G., 1989. 40Ar/39Ar total gas ages of basalts from Notera 3 well, Hula Valley, Dead Sea Rift: stratigraphic and tectonic implications. Israel journal of earth sciences 38, 173-184.

Herman, F., Rhodes, E.J., Braun, J., Heiniger, L., 2010. Uniform erosion rates and relief amplitude during glacial cycles in the Southern Alps of New Zealand, as revealed from OSL-thermochronology. Earth and Planetary Science Letters 297, 183-189.

Jain, M., 2009. Extending the dose range: Probing deep traps in quartz with $3.06 \mathrm{eV}$ photons. Radiation Measurements 44, 445-452.

Jain, M., Bøtter-Jensen, L., Murray, A.S., Denby, P.M., Tsukamoto, S., Gibling, M.R., 2005. Revisiting TL: dose measurement beyond the OSL range using SAR. Ancient TL 23, 9-24.

Lai, Z. and Fan, A., 2014. Examining quartz OSL age underestimation for loess samples from Luochuan in the Chinese Loess Plateau. Geochronometria 41, 57-64.

Lepper, K. and Goff, F., 2007. Yet another attempt to date the Banco Bonito rhyolite, the youngest volcanic flow in the Valles caldera, New Mexico. New Mexico Geology 29(4).

Mor, D. and Steinitz, G., 1984. K-Ar age of the basalts at Nahal Orvim (Northern Golan heights). Geological Survey of Israel Report nr. GSI/37/84.

Ogoh, K., Toyoda, S., Ikeda, S., Ikeya, M., Goff, F., 1993. Cooling history of the Valles Caldera, New Mexico using ESR dating method. Applied Radiation and Isotopes 44, 233 237.

Porat, N., 2006. Use of magnetic separation for purifying quartz for luminescence dating. Ancient TL 24, 33-36.

Prescott, J.R. and Hutton, J.T., 1994. Cosmic ray contributions to dose rates for luminescence and ESR dating: large depths and long-term time variations. Radiation measurements 23, 497-500.

Preusser, F., Chithambo, M.L., Götte, T., Martini, M., Ramseyer, K., Sendezera, E.J., Susino, G.J., Wintle, A.G., 2009. Quartz as a natural luminescence dosimeter. Earth-Science Reviews 97, 184-214.

Reiners, P.W., Brandon, M.T., 2006. Using thermochronology to understand orogenic erosion. Annu. Rev. Earth Planet. Sci. 34, 419-466.

Roded, R., Shalev, E., Katoshevski, D., 2013. Basal heat-flow and hydrothermal regime at the Golan-Ajloun hydrological basins. Journal of Hydrology 476, 200-211.

Shalev, E., Lyakhovsky, V., Weinstein, Y., Ben-Avraham, Z., 2013. The thermal structure of Israel and the Dead Sea Fault. Tectonophysics 602, 69-77.

Siebert, C., Möller, P., Geyer, S., Kraushaar, S., Dulski, P., Guttman, J., Subah, A., Rödiger, T., 2014. Thermal waters in the Lower Yarmouk Gorge and their relation to surrounding aquifers. Chemie der Erde 74, 425-441.

Singarayer, J.S., Bailey, R.M., Rhodes, E.J., 2000. Potential of the slow component of quartz OSL for age determination of sedimentary samples. Radiation Measurements 32, 873-880.

Singer, A. and Ben-Dor, E., 1987. Origin of red clay layers interbedded with basalts of the Golan Heights. Geoderma 39, 293-306. 
Singer, B.S., 2014. A Quaternary geomagnetic instability time scale. Quaternary Geochronology 21, 29-52.

Timar-Gabor, A. and Wintle, A.G., 2013. On natural and laboratory generated dose response curves for quartz of different grain sizes from Romanian loess. Quaternary Geochronology $18,34-40$.

Tsukamoto, S., Duller, G.A.T., Wintle, A.G., Muhs, D., 2011. Assessing the potential for luminescence dating of basalts. Quaternary Geochronology 6, 61-70.

Vandenberghe, D., De Corte, F., Buylaert, J.P., Kučera, J., 2008. On the internal radioactivity in quartz. Radiation Measurements 43, 771-775.

Weinstein, Y., Garfunkel, Z., 2014. The Dead Sea Transform and the Volcanism in Northwestern Arabia. In Dead Sea Transform Fault System: Reviews. Springer Netherlands.

Wintle, A.G., 2008. Luminescence dating: where it has been and where it is going. Boreas 37, 471-482.

Wintle, A.G., Murray, A.S., 2006. A review of quartz optically stimulated luminescence characteristics and their relevance in single-aliquot regeneration dating protocols. Radiation Measurements 41, 369-391.

Wu, T.-S., Jain, M., Guralnik, B., Murray, A.S., Chen, Y.-G. 2015. Luminescence characteristics of quartz from Hsuchshan Range (Central Taiwan) and the implications as a thermochronometer, this volume, Radiation Measurements 